\title{
What is the impact of socioeconomic status on multiple sclerosis?
}

Devon S. Conway, MD

Neurology ${ }^{\circledR}$ 2019;92:e1536-e1539. doi:10.1212/WNL.0000000000007166

\section{What did the authors study?}

In "Socioeconomic status and disability progression in multiple sclerosis: a multinational study," Dr. Katharine Harding ${ }^{1}$ and her colleagues considered whether people's income, education, and social standing affected how quickly their multiple sclerosis (MS) worsened. The rate at which MS causes worsening of cognitive and physical functioning can vary. The reasons for these differences are not clear but are interesting because they may lead to better treatment for MS.

\section{How was the study done?}

To see if socioeconomic status (SES) affected MS-related disability, the authors reviewed 2 databases containing information on patients with MS. One was from British Columbia, Canada, and the other from Cardiff, Wales, United Kingdom. These databases have been kept since the 1980 s and have patient information. This includes date of diagnosis and disability scores over time. In Canada, the database information was linked to records from the provincial health system. In Wales, it was linked to National Health Service records. The data were used to estimate each patient's SES based on where the patient lived. The patients were divided into 5 groups based on their SES. Group 1 were those with the lowest SES and group 5 were those with the highest SES.

The authors used statistics to analyze the relationship between SES and worsening of disability scores. The influence of SES on the time it took patients to change from relapsing-remitting MS to secondary progressive multiple sclerosis (SPMS) was also studied. This is important because patients with SPMS become disabled more quickly and do not respond well to treatment. The authors also made changes to account for differences such as age and sex among their study populations so that any findings could be attributed to differences in SES and not these other factors.

\section{What did the study find?}

There were 3,113 patients with enough information to be included. The authors found that being one step higher in SES status (for example, group 3 vs group 2) reduced a patient's risk of eventually needing a cane by $10 \%$. Individuals in group 5 (highest SES) had almost a $40 \%$ lower risk of eventually needing a cane than those in group 1 (lowest SES). The authors also discovered that the risk of developing SPMS was reduced by $6 \%$ by each higher SES step.

\section{What do these results mean?}

Other research has shown that people with lower incomes and less education tend to have worse outcomes with a number of conditions, such as high blood pressure and diabetes. ${ }^{2,3}$ The authors of this study were able to extend those findings to MS by showing that patients with MS and lower SES become disabled faster and transition to SPMS faster. These results were consistent across 2 different countries, so they were probably not related to societal differences. A possible problem with this study is that patients with the worst MS are likely to have the

\section{RELATED ARTICLE}

Socioeconomic status and disability progression in multiple sclerosis: A multinational study

Page e1497 
lowest SES. This is because MS can change how much a patient can work and earn. However, the authors considered this by using the SES at the time of diagnosis rather than at a point after diagnosis, thereby lessening the influence of MS-related disability.

Looking at the differences between patients with MS with higher and lower SES might be an effective treatment strategy for the disease. The reason why individuals with higher SES have less progression in their disability needs to be studied. One reason could be that patients with higher SES have better access to high-quality care. Other ideas include high-quality care. Or they might have better social support, eat healthier foods, or have healthier habits. These issues need to be studied so that programs and policies can better address the needs of patients with MS with lower SES. This approach, along with addressing their medical needs, will hopefully reduce worsening of disability and improve the quality of life for patients with MS. 


\section{About multiple sclerosis}

Devon S. Conway, MD

Neurology ${ }^{\circledR}$ 2019;92:e1536-e1539. doi:10.1212/WNL.0000000000007166

\section{What is multiple sclerosis?}

Multiple sclerosis (MS) is a disease that affects the CNS: the brain, optic nerves, and spinal cord. ${ }^{4}$ Nerve cells in the CNS talk to each other through electrical and chemical signals. Like the wiring in a home, nerve cells require insulation, called myelin, to transfer signals electrically. In MS, an individual's immune system, which typically fights off infections, changes and begins removing myelin from nerve cells. This is why MS is often referred to as a demyelinating disease. Without the myelin for insulation, nerve cells can short circuit and malfunction, which is what causes MS symptoms. The nerve cells also may degenerate and die, though the reasons why are unclear.

\section{What causes MS and how can it be prevented?}

The cause of MS is unknown, but a person's genetic makeup (DNA) can put him or her at higher risk for the disease. Those with Northern European ancestry are more likely to develop MS. Other risk factors include being a woman, having low vitamin D, living far from the equator, cigarette smoking, infection with the Epstein-Barr virus in adolescence, or obesity in early life. The mix of genetic factors, environmental exposures, and lifestyle behaviors is complex and how they lead one to develop MS is being studied.

There is no known way to prevent MS. To lower one's chances of MS, it may be helpful to pay attention to risk factors that can be controlled. For instance, keeping a healthy weight, avoiding smoking, and vitamin $\mathrm{D}$ intake might be protective.

\section{What are the symptoms of MS?}

Because MS can affect any part of the CNS, it can cause many symptoms. Common initial symptoms may include loss of vision in one eye, double vision, numbness, or weakness. Other symptoms that patients with MS frequently have include fatigue, stiffness of the muscles, bowel and bladder problems, and difficulty walking. Most patients with MS also experience some problems with how well they remember things and how quickly they can think.

\section{How is MS treated?}

Changes in the immune system lead to MS. There are more than 10 approved treatments for MS in the United States. They work by changing the action of the immune system. For instance, one treatment affects how immune cells can enter the brain. Another treatment leads to destruction of the immune cells that produce antibodies. MS treatments are given in different ways, including by shot, by mouth, or through an IV. It is difficult to know how a patient will respond to a medication, so different treatments may need to be tried before the best one is found.

Other treatments are being studied, including for progressive MS, which does not respond well to already approved therapies. One approach is to use medication to stimulate the replacement of damaged nerve cell insulation. This is called remyelinating therapy. ${ }^{5}$ There is also interest in developing treatments that keep injured nerve cells from degenerating. Such therapies are referred to as being neuroprotective. ${ }^{4}$ Stem cells may have remyelinating and neuroprotective qualities, and they are also being investigated as a new MS treatment. 
Helping with MS symptoms is another important part of caring for patients with MS. Medications are available that can address symptoms such as depression, muscle stiffness, and numbness and tingling. Physical, occupational, and speech therapy also play an important role and can help patients with issues like unsteadiness, fatigue, and swallowing difficulties. A multidisciplinary approach to MS is recommended and might involve other professionals like psychologists or social workers.

\section{For more information \\ Brain \& Life}

brainandlife.org/
The National Multiple Sclerosis Society

nationalmssociety.org/Resources-Support

\section{References}

1. Harding KE, Wardle M, Carruthers R, et al. Socioeconomic status and disability progression in multiple sclerosis: a multinational study. Neurology 2019;92: e1497-e1506.

2. Leng B, Jin Y, Li G, Chen L, Jin N. Socioeconomic status and hypertension. J Hypertens 2015;33:221-229.

3. Jaffiol C, Thomas F, Bean K, Jégo B, Danchin N. Impact of socioeconomic status on diabetes and cardiovascular risk factors: results of a large French survey. Diabetes Metab 2013;39:56-62.

4. Thompson AJ, Baranzini SE, Geurts J, Hemmer B, Ciccarelli O. Multiple sclerosis. Lancet 2018;391:1622-1636.

5. Gholamzad M, Ebtekar M, Ardestani MS, et al. A comprehensive review on the treatment approaches of multiple sclerosis: currently and in the future. Inflamm Res 2019;68:25-38. 


\section{Neurology}

\section{What is the impact of socioeconomic status on multiple sclerosis?}

Devon S. Conway

Neurology 2019;92; 1536-e1539

DOI 10.1212/WNL.0000000000007166

\section{This information is current as of March 25, 2019}

\section{Updated Information \&} Services

References

Permissions \& Licensing

Reprints including high resolution figures, can be found at: http://n.neurology.org/content/92/13/e1536.full

This article cites 5 articles, 1 of which you can access for free at: http://n.neurology.org/content/92/13/e1536.full\#ref-list-1

Information about reproducing this article in parts (figures,tables) or in its entirety can be found online at:

http://www.neurology.org/about/about_the_journal\#permissions

Information about ordering reprints can be found online:

http://n.neurology.org/subscribers/advertise

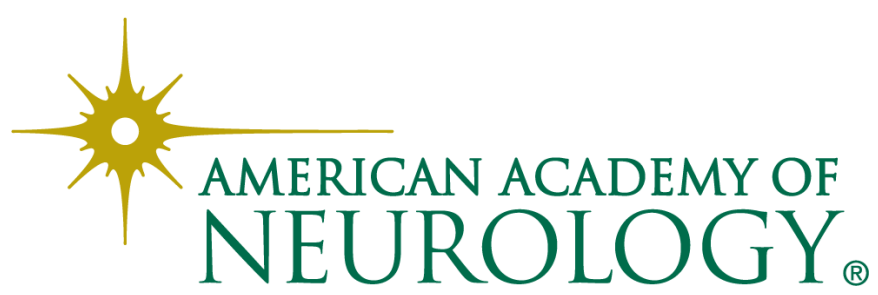

